This item was submitted to Loughborough's Research Repository by the author.

Items in Figshare are protected by copyright, with all rights reserved, unless otherwise indicated.

\title{
Seasonal unit root tests with seasonal mean shifts
}

PLEASE CITE THE PUBLISHED VERSION

LICENCE

CC BY-NC-ND 4.0

\section{REPOSITORY RECORD}

Harvey, David I., Stephen J. Leybourne, and Paul Newbold. 2019. "Seasonal Unit Root Tests with Seasonal Mean Shifts". figshare. https://hdl.handle.net/2134/427. 
This item was submitted to Loughborough's Institutional Repository by the author and is made available under the following Creative Commons Licence conditions.

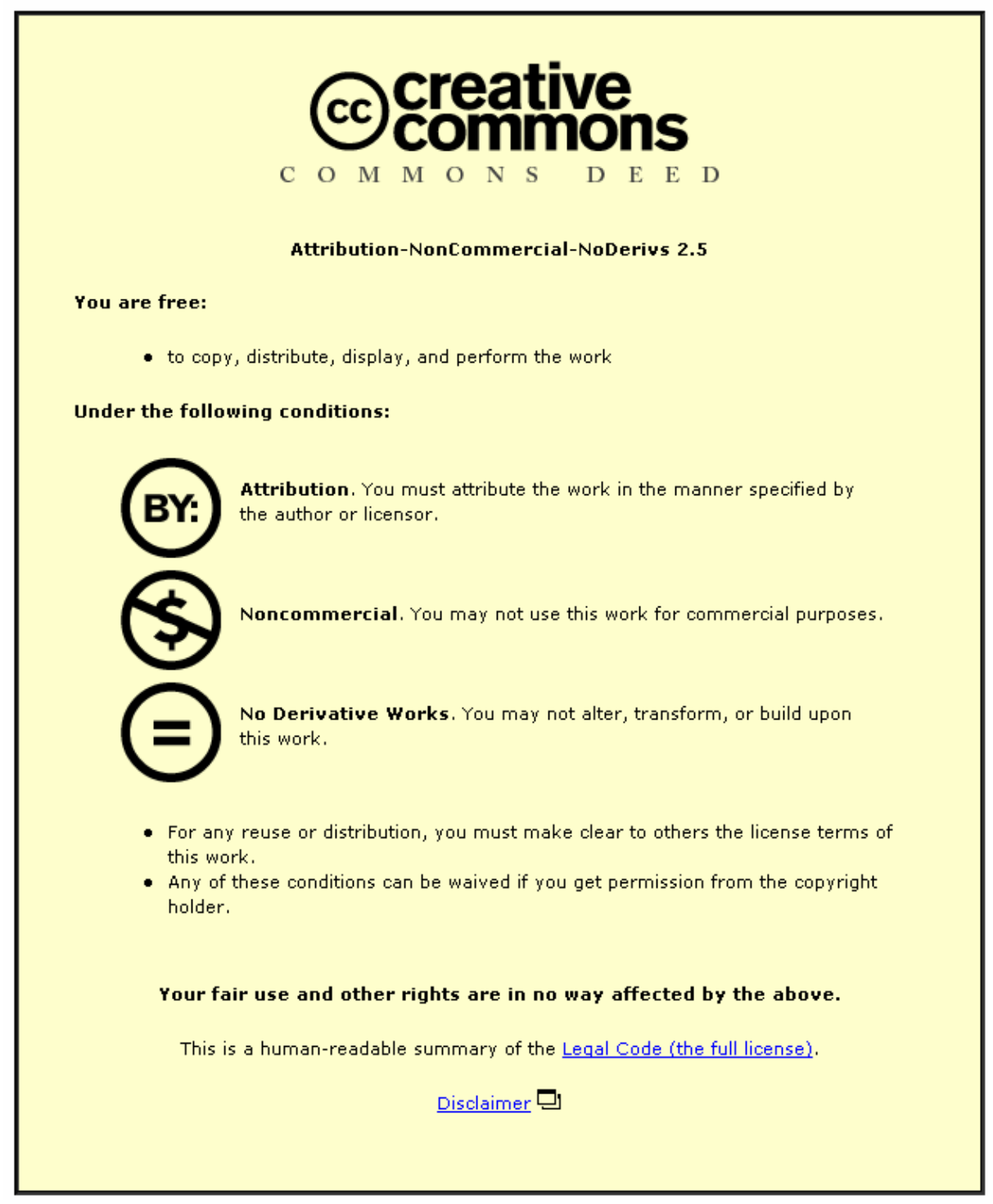

For the full text of this licence, please go to: http://creativecommons.org/licenses/by-nc-nd/2.5/ 
Department of Economics

Economic Research Paper No. 01/5

\section{Seasonal Unit Root Tests with Seasonal Mean Shifts}

David I. Harvey, Stephen J. Leybourne and Paul Newbold

July 2001 
Centre for International, Financial and Economics Research Department of Economics Loughborough University Loughborough Leics., LE11 3TU UK

Tel: $+44(0) 1509222734$ Fax: + $44(0) 1509223910$

Email: E.J.Pentecost@lboro.ac.uk

Director : $\quad$ Dr Eric J Pentecost

Deputy Director : Professor C J Green

Associate Directors:

Professor Kenneth J Button, George Mason University, USA Professor Peter Dawkins, University of Melbourne, Australia Professor Robert A Driskill, Vanderbilt University, USA Professor James Gaisford, University of Calgary, Canada Professor Andre van Poeck, University of Antwerp, Belgium Professor Amine Tarazi, University of Limoges, France 


\title{
Seasonal unit root tests with seasonal mean shifts
}

\author{
David I. Harvey ${ }^{*}$ \\ Department of Economics, Loughborough University, Loughborough, Leicestershire, LE11 3TU, UK \\ Stephen J. Leybourne and Paul Newbold \\ School of Economics, University of Nottingham, University Park, Nottingham, NG7 2RD, UK
}

\begin{abstract}
This paper analyses additive outlier and innovational outlier tests for seasonal unit roots when seasonal mean shifts occur under the null hypothesis. When the magnitude of the breaks is large, simulation evidence reveals that, for three of the four testing procedures considered, the endogenously determined break point can be incorrectly estimated, resulting in spurious rejections of the null. A simple modification to one of the testing approaches is proposed which achieves a substantial improvement in test size.
\end{abstract}

Keywords: Seasonal unit roots; structural breaks; spurious rejections.

JEL classification: $\mathrm{C} 12 ; \mathrm{C} 22$

* Corresponding author. Tel.: +44 (0)1509 222712; fax: +44 (0)1509 223910; e-mail: D.I.Harvey@Lboro.ac.uk 


\section{Introduction}

Modelling seasonal time series, and in particular determining whether the underlying seasonality is best described by a deterministic process or one with stochastic trends at seasonal frequencies, has received much attention in the recent literature. Hylleberg et al. (1990), henceforth HEGY, first proposed tests for seasonal unit roots against a simple alternative hypothesis of stationarity around deterministic seasonality. A number of authors Ghysels (1994), Paap et al. (1997), Smith and Otero (1997), Lopes and Montañés (2000), and Lopes (2001) - have subsequently considered the possibility of models involving structural breaks in deterministic seasonality, and the influence of such seasonal mean shifts on testing for seasonal unit roots using HEGY-type procedures. Further to this end, Franses and Vogelsang (1998) and Balcombe (1999) have proposed seasonal unit root testing procedures which explicitly account for potential seasonal mean shifts, the tests comprising seasonal counterparts to the additive outlier and innovational outlier tests developed by, inter alia, Perron $(1989,1993)$ and Perron and Vogelsang (1992) in a non-seasonal setting. ${ }^{1}$

The aforementioned non-seasonal unit root tests allow the timing of a potential structural break to be determined endogenously using one of two methodologies, both of which involve fitting Dickey-Fuller-type regressions for all possible break dates. The first approach follows Zivot and Andrews (1992) and selects the break date for which the unit root test statistic is a minimum (i.e. least favourable to the null hypothesis); the second chooses the date for which the coefficient on the appropriate dummy variable is most significant (i.e. the most likely position of the break). In this non-seasonal context, Harvey et al. (2001) showed that the innovational outlier test using both break date selection methods and the additive outlier test using Zivot-Andrews break date estimation are severely over-sized when a large break occurs under the null hypothesis, the problem arising from an incorrect choice of break date in the limit when the magnitude of the break is asymptotically non-negligible.

Since the seasonal unit root tests of Franses and Vogelsang (1998) and Balcombe (1999) parallel the non-seasonal procedures discussed above, it is interesting to explore whether the tests are similarly over-sized when large seasonal mean shifts occur under the null hypothesis. This paper investigates such a proposition using Monte Carlo simulation and is structured as follows: Section 2 outlines the extant seasonal unit root tests which allow for seasonal mean shifts, Section 3 considers the tests' behaviour in the presence of large breaks

\footnotetext{
${ }^{1}$ Franses et al. (1997) also consider analysis of series for seasonal unit roots in the presence of seasonal mean shifts, and propose procedures using Bayesian techniques.
} 
under the null and presents a simple modification for one test which yields an improvement in empirical size, and Section 4 concludes.

\section{Seasonal unit root tests with seasonal mean shifts}

For the quarterly time series $y_{t}$, observed for $t=1, \ldots, T$, the Franses-Vogelsang seasonal unit root tests assume the following model under the null hypothesis:

$$
y_{t}=\sum_{s=1}^{4} \kappa_{s} D\left(T_{B}^{\prime}\right)_{s t}+y_{t-4}+\varepsilon_{t}
$$

where $\varepsilon_{t}$ is $\operatorname{iid}\left(0, \sigma^{2}\right), D\left(T_{B}^{\prime}\right)_{s t}=\Delta_{4} D U_{s t}$ with $D U_{s t}=1\left(t>T_{B}^{\prime}\right) D_{s t}, 1($.$) being the$ indicator function and $D_{s t}$ being seasonal dummies $(s=1,2,3,4)$. The model therefore involves one non-seasonal and three seasonal unit roots, whilst also admitting the possibility of a structural break in each season at time $T_{B}^{\prime}$. Although not considered in this paper for purposes of tractability, a more general autocorrelation structure can also be assumed (see Franses and Vogelsang, 1998).

The additive outlier test then follows a two step procedure, first fitting the regression

$$
y_{t}=\sum_{s=1}^{4} \mu_{s} D_{s t}+\sum_{s=1}^{4} \delta_{s} D U_{s t}+e_{t}
$$

The second step involves estimating a HEGY-type auxiliary regression based on the residuals from (2):

$$
\Delta_{4} \hat{e}_{t}=\pi_{1} \hat{e}_{1, t-1}+\pi_{2} \hat{e}_{2, t-1}+\pi_{3} \hat{e}_{3, t-2}+\pi_{4} \hat{e}_{3, t-1}+\sum_{s=1}^{4} \theta_{s} D\left(T_{B}^{\prime}\right)_{s, t}+\sum_{i=1}^{4} \omega_{i} D\left(T_{B}^{\prime}\right)_{4, t-i}+\varepsilon_{t}
$$

where

$$
\hat{e}_{1 t}=\left(1+L+L^{2}+L^{3}\right) \hat{e}_{t}, \quad \hat{e}_{2 t}=-\left(1-L+L^{2}-L^{3}\right) \hat{e}_{t}, \quad \hat{e}_{3 t}=-\left(1-L^{2}\right) \hat{e}_{t}
$$

On the other hand, the innovational outlier test is based on the single regression

$$
\begin{aligned}
\Delta_{4} y_{t}= & \pi_{1} y_{1, t-1}+\pi_{2} y_{2, t-1}+\pi_{3} y_{3, t-2}+\pi_{4} y_{3, t-1}+\sum_{s=1}^{4} \mu_{s} D_{s t} \\
& +\sum_{s=1}^{4} \delta_{s} D U_{s t}+\sum_{s=1}^{4} \kappa_{s} D\left(T_{B}^{\prime}\right)_{s t}+\varepsilon_{t}
\end{aligned}
$$

where

$$
y_{1 t}=\left(1+L+L^{2}+L^{3}\right) y_{t}, \quad y_{2 t}=-\left(1-L+L^{2}-L^{3}\right) y_{t}, \quad y_{3 t}=-\left(1-L^{2}\right) y_{t}
$$

The regressions (3) and (4) derive from the decomposition of $\Delta_{4}$ as $(1-L)(1+L) \times$ $(1-i L)(1+i L)$ where $L$ is the lag operator. When $\pi_{1}=0$ the $(1-L)$ filter is needed, 
corresponding to a non-seasonal unit root; when $\pi_{2}=0$ the $(1+L)$ filter is necessary, corresponding to a seasonal unit root at the biannual frequency; and when $\pi_{3}=\pi_{4}=0$ the $\left(1+L^{2}\right)$ filter is required, corresponding to seasonal unit roots $\pm i$ at the annual frequency. The relevant test statistics in each case are thus the $t$-ratios on $\pi_{1}$ and $\pi_{2}$ (denoted $t_{1}$ and $t_{2}$ respectively), and the $F$-statistic for the joint significance of $\pi_{3}$ and $\pi_{4}$ (denoted $F_{34}$ ).

Note however that the true break date $T_{B}^{\prime}$ appearing in (2), (3) and (4) is unknown and must therefore be replaced with an estimate $\hat{T}_{B}$ which can be determined endogenously. Franses and Vogelsang (1998) consider two methods of break date estimation, both of which involve conducting the tests for all possible assumed break dates $T_{B}$. The first uses a ZivotAndrews approach, selecting the break date where the test statistic of interest is least favourable to the null, i.e.,

$$
\begin{array}{ll}
\hat{T}_{B}=\operatorname{argmin} t_{i}\left(T_{B}\right) & \text { for test } t_{i}, i=1,2 \\
\hat{T}_{B}=\operatorname{argmax} F_{34}\left(T_{B}\right) & \text { for test } F_{34}
\end{array}
$$

The second chooses the break date which maximises the significance of the seasonal mean shift dummy variable coefficients in (2) or (4), i.e.,

$$
\hat{T}_{B}=\operatorname{argmax} F_{\delta}\left(T_{B}\right)
$$

Balcombe (1999) proposes similar tests to those outlined above, although the important one-time dummy variables in (3) and (4) above are omitted, and only break date estimation using (5) is considered.

\section{Test behaviour in the presence of large breaks under the null}

In order to analyse the behaviour of the Franses-Vogelsang seasonal unit root tests when there are large seasonal mean shifts under the null, we conducted a series of Monte Carlo simulation experiments with the generating process given by (1). A practically interesting sample size of $T=100$ was used with a true break date $T_{B}^{\prime}=48$. Using a single break parameter $\kappa$, we evaluated the empirical sizes of the tests, considering a variety of possible combinations of seasonal mean shifts with relatively large break sizes of $\kappa=5$ and $\kappa=10$ :

(1) Change in overall mean only: $\kappa_{1}=\kappa_{2}=\kappa_{3}=\kappa_{4}=\kappa$

(2) Change in overall mean and seasonal pattern:

(i) Break in one season: e.g. $\kappa_{1}=\kappa, \kappa_{2}=\kappa_{3}=\kappa_{4}=0$

(ii) Breaks in two seasons: e.g. $\kappa_{1}=\kappa_{2}=\kappa, \kappa_{3}=\kappa_{4}=0$

(iii) Breaks in three seasons: e.g. $\kappa_{1}=\kappa_{2}=\kappa_{3}=\kappa, \kappa_{4}=0$ 
(3) Change in seasonal pattern only:

(i) Breaks in two seasons: e.g. $\kappa_{1}=\kappa, \kappa_{2}=-\kappa, \kappa_{3}=\kappa_{4}=0$

(ii) Breaks in all seasons: e.g. $\kappa_{1}=\kappa, \kappa_{2}=-\kappa, \kappa_{3}=\kappa, \kappa_{4}=-\kappa$

For each of the cases listed above, we report examples of all combinations of breaks which give distinct results; other possible combinations in each category that are not reported in the tables yielded the same results apart from sampling variability. Here and throughout the paper, the permitted range of possible break dates was $20 \leq T_{B} \leq 80$; all the experiments used 10,000 replications and the calculations were programmed in GAUSS.

Table 1 reports the results of these empirical size simulations. When the break date is estimated using the Zivot-Andrews method (5), the additive and innovational outlier tests are severely over-sized in all cases, the problem worsening with the magnitude of the break. The innovational outlier test exhibits similar behaviour when the break point is chosen using (6), although the additive outlier test does not suffer such problems, and is in fact a little undersized in these cases.

Harvey et al. (2001) examined the innovational outlier test in the non-seasonal case, and showed that the $t$-ratio associated with the shift dummy variable used to select the break date (non-seasonal counterpart to (6)) has an asymptotic distribution whose absolute mean is maximised at $T_{B}^{\prime}-1$ when large breaks occur under the null. It is this feature of incorrect break date estimation in the limit that drives the size distortions reported in that paper. An equivalent simulation analysis here displays an interesting parallel. Table 2 provides results for the percentage of times particular break dates are selected in the same simulation experiments described above, when the innovational outlier test with (6) is employed. It can be seen that when large seasonal mean shifts occur, the estimation rule (6) almost invariably places the break date incorrectly at $T_{B}^{\prime}-4$. (Note that in a number of cases, for example when $\kappa_{1}=\kappa, \kappa_{2}=\kappa_{3}=\kappa_{4}=0$, break dates of $T_{B}^{\prime}-7, T_{B}^{\prime}-6$ and $T_{B}^{\prime}-5$ are equivalent to a break date of $T_{B}^{\prime}-4$. This follows since $T_{B}^{\prime}=48$, thus if a break occurs at, say $T_{B}^{\prime}-7$, the dummy variable $D_{1 t}$ is not operative until $T_{B}^{\prime}-4$.) This parallel result to the non-seasonal unit root test is the reason for the pattern of over-size observed in Table 1.

The obvious modification to correct for this problem is simply to adjust the estimation rule to choose the break date four observations later than (6) would suggest, i.e.

$$
\hat{T}_{B}=4+\operatorname{argmax} F_{\delta}\left(T_{B}\right)
$$


Although the limiting distribution of the seasonal unit root test statistics using this criterion will be the same as that associated with use of (6), the critical values will be different in finite samples. Table 3 provides critical values for the three tests $\left(t_{1}, t_{2}, F_{34}\right)$ when the break date is estimated using (7), for a number of practically relevant sample sizes. These critical values were derived by simulation using driftless random walks without breaks as the generating process.

To evaluate the performance of the above modification, the simulation experiments associated with Table 1 were repeated, but using tests involving the new break date selection rule (7) and the critical values reported in Table 2 . The results are given in Table 4 . The size of the modified test can be seen to be much more reliable than the standard approach, with the pattern of serious over-size removed. The estimated break dates are shifted four periods forward of those given by the original procedure, thereby correcting the problem observed in Table 2 and the associated spurious rejection phenomenon. The disadvantage of the modified approach is its tendency to be somewhat under-sized, more so for larger break sizes.

\section{Conclusion}

It is useful to have available techniques for testing for seasonal unit roots when seasonal mean shifts occur under the null hypothesis. We have analysed the behaviour of such tests (for quarterly data) when the magnitude of the breaks is large. Simulation evidence shows that when the innovational outlier test is used with the preferred method of choosing the break date on the basis of the significance of shift dummy variables, the break point is incorrectly placed too soon, causing spurious rejection of the null hypothesis. A modification involving a simple correction to the break date estimation criterion achieves a substantial improvement in test size.

It is also noteworthy that the equivalent additive outlier test (where the break date is also chosen according to the significance of dummy variables) does not suffer from problems of test over-size. This parallels the results of Harvey et al. (2001) in the non-seasonal context, and suggests that this procedure has some inherent advantages over the innovational outlier approach. 


\section{References}

Balcombe, K., 1999. Seasonal unit root tests with structural breaks in deterministic seasonality. Oxford Bulletin of Economics and Statistics 61, 569-82.

Franses, P.H., Hoek, H. and Paap, R., 1997. Bayesian analysis of seasonal unit roots and seasonal mean shifts. Journal of Econometrics 78, 359-80.

Franses, P.H. and Vogelsang, T.J., 1998. On seasonal cycles, unit roots, and mean shifts. Review of Economics and Statistics 80, 231-40.

Ghysels, E., 1994. On the economics and econometrics of seasonality. In Sims, C.A. (Ed.), Advances in Econometrics, Sixth World Congress, Vol. I. Cambridge University Press, pp. 257-322.

Harvey, D.I., Leybourne, S.J. and Newbold, P., 2001. Innovational outlier unit root tests with an endogenously determined break in level. Discussion Paper. Department of Economics, University of Nottingham.

Hylleberg, S., Engle, R.F., Granger, C.W.J. and Yoo, B.S., 1990. Seasonal integration and cointegration. Journal of Econometrics 44, 215-38.

Lopes, A.C.B. da S., 2001. The robustness of tests for seasonal differencing to structural breaks. Economics Letters 71, 173-9.

Lopes, A.C.B. da S. and Montañés, A., 2000. The behaviour of seasonal unit root tests for quarterly time series with seasonal mean shifts. Discussion Paper. Instituto Superior de Economia e Gestão.

Paap, R., Franses, P.H. and Hoek, H., 1997. Mean shifts, unit roots and forecasting seasonal time series. International Journal of Forecasting 13, 357-68.

Perron, P., 1989. The Great Crash, the oil price shock, and the unit root hypothesis. Econometrica 57, 1361-1401.

Perron, P., 1993. The Great Crash, the oil price shock, and the unit root hypothesis: Erratum. Econometrica 61, 248-9.

Perron, P. and Vogelsang, T.J., 1992. Nonstationarity and level shifts with an application to purchasing power parity. Journal of Business and Economic Statistics 10, 301-20.

Smith, J. and Otero, J., 1997. Structural breaks and seasonal integration. Economics Letters $56,13-19$.

Zivot, E. and Andrews, D.W.K., 1992. Further evidence on the Great Crash, the oil price shock, and the unit-root hypothesis. Journal of Business and Economic Statistics 10, 25170 . 
Table 1. Empirical sizes of nominal 5\%-level seasonal unit root tests, allowing for seasonal mean shifts: $T=100$.

\begin{tabular}{|c|c|c|c|c|c|c|c|c|c|c|c|c|c|c|c|}
\hline \multirow[b]{3}{*}{$\kappa_{1}$} & \multirow[b]{3}{*}{$\kappa_{2}$} & \multirow[b]{3}{*}{$\kappa_{3}$} & \multirow[b]{3}{*}{$\kappa_{4}$} & \multicolumn{6}{|c|}{ Additive outlier tests } & \multicolumn{6}{|c|}{ Innovational outlier tests } \\
\hline & & & & \multicolumn{3}{|c|}{$\hat{T}_{B}=\operatorname{argmin} t_{i} / \operatorname{argmax} F_{34}$} & \multicolumn{3}{|c|}{$\hat{T}_{B}=\operatorname{argmax} F_{\delta}$} & \multicolumn{3}{|c|}{$\hat{T}_{B}=\operatorname{argmin} t_{i} / \operatorname{argmax} F_{34}$} & \multicolumn{3}{|c|}{$\hat{T}_{B}=\operatorname{argmax} F_{\delta}$} \\
\hline & & & & $t_{1}$ & $t_{2}$ & $F_{34}$ & $t_{1}$ & $t_{2}$ & $F_{34}$ & $t_{1}$ & $t_{2}$ & $F_{34}$ & $t_{1}$ & $t_{2}$ & $F_{34}$ \\
\hline 5 & 5 & 5 & 5 & 78.70 & 30.14 & 54.76 & 4.25 & 4.49 & 4.86 & 87.27 & 21.85 & 43.13 & 86.46 & 6.32 & 15.49 \\
\hline 5 & 0 & 0 & 0 & 9.34 & 9.72 & 12.39 & 5.18 & 5.24 & 5.26 & 10.84 & 11.74 & 15.18 & 10.96 & 12.27 & 14.41 \\
\hline 5 & 5 & 0 & 0 & 29.15 & 18.25 & 30.68 & 4.49 & 5.38 & 4.95 & 38.79 & 13.73 & 35.69 & 38.55 & 5.75 & 30.38 \\
\hline 5 & 0 & 5 & 0 & 27.00 & 28.00 & 21.28 & 4.73 & 4.43 & 5.72 & 37.67 & 38.62 & 16.73 & 37.37 & 38.50 & 7.56 \\
\hline 5 & 0 & 0 & 5 & 21.08 & 18.46 & 25.56 & 4.44 & 5.50 & 5.42 & 32.40 & 14.42 & 30.74 & 35.24 & 6.84 & 28.79 \\
\hline 5 & 5 & 5 & 0 & 56.65 & 18.56 & 42.96 & 4.45 & 4.73 & 5.26 & 69.15 & 18.42 & 39.65 & 68.03 & 10.49 & 23.54 \\
\hline 5 & 5 & 0 & 5 & 53.99 & 32.40 & 28.11 & 4.31 & 4.74 & 4.85 & 68.11 & 30.54 & 27.08 & 67.52 & 20.12 & 13.22 \\
\hline 5 & 0 & 5 & 5 & 55.13 & 28.97 & 33.02 & 4.35 & 4.69 & 4.97 & 68.30 & 26.79 & 31.46 & 69.90 & 10.39 & 24.46 \\
\hline 5 & -5 & 0 & 0 & 18.54 & 30.32 & 30.46 & 5.67 & 4.45 & 5.17 & 14.40 & 40.15 & 35.49 & 6.34 & 39.76 & 30.79 \\
\hline 5 & 0 & -5 & 0 & 19.00 & 19.05 & 43.25 & 5.89 & 5.34 & 4.29 & 14.20 & 14.40 & 54.11 & 6.47 & 6.23 & 55.71 \\
\hline 5 & 0 & 0 & -5 & 17.96 & 22.17 & 25.38 & 5.63 & 4.32 & 5.27 & 13.86 & 34.26 & 30.54 & 6.98 & 36.74 & 29.09 \\
\hline 5 & 5 & -5 & -5 & 41.61 & 34.88 & 79.39 & 4.48 & 4.58 & 4.38 & 33.09 & 25.70 & 86.34 & 9.42 & 7.69 & 85.70 \\
\hline 5 & -5 & 5 & -5 & 30.16 & 78.85 & 54.50 & 4.60 & 4.17 & 4.82 & 22.01 & 87.08 & 42.60 & 6.41 & 86.47 & 15.68 \\
\hline 5 & -5 & -5 & 5 & 34.96 & 43.21 & 79.70 & 4.67 & 4.45 & 4.26 & 25.79 & 35.05 & 86.42 & 7.67 & 9.81 & 85.74 \\
\hline 10 & 10 & 10 & 10 & 99.75 & 73.74 & 98.86 & 4.07 & 4.01 & 3.86 & 99.89 & 61.18 & 96.01 & 99.46 & 22.77 & 68.95 \\
\hline 10 & 0 & 0 & 0 & 40.17 & 41.29 & 59.89 & 4.44 & 4.34 & 4.32 & 47.11 & 48.54 & 67.81 & 39.98 & 41.24 & 53.83 \\
\hline 10 & 10 & 0 & 0 & 88.57 & 60.77 & 91.88 & 4.39 & 4.33 & 4.15 & 93.03 & 48.61 & 94.78 & 78.98 & 14.74 & 70.70 \\
\hline 10 & 0 & 10 & 0 & 86.03 & 86.13 & 73.73 & 4.36 & 4.18 & 3.98 & 91.99 & 92.00 & 61.76 & 80.82 & 80.94 & 28.47 \\
\hline 10 & 0 & 0 & 10 & 76.33 & 59.19 & 88.78 & 4.08 & 4.01 & 3.88 & 87.58 & 50.35 & 93.12 & 86.73 & 20.91 & 89.29 \\
\hline 10 & 10 & 10 & 0 & 97.61 & 55.90 & 96.59 & 4.35 & 4.17 & 3.97 & 98.99 & 61.21 & 96.77 & 94.60 & 30.37 & 70.80 \\
\hline 10 & 10 & 0 & 10 & 97.48 & 84.65 & 84.05 & 4.07 & 4.02 & 3.86 & 98.97 & 80.63 & 86.13 & 95.55 & 77.77 & 47.69 \\
\hline 10 & 0 & 10 & 10 & 97.91 & 82.28 & 91.33 & 4.08 & 4.01 & 3.86 & 98.92 & 78.59 & 90.50 & 96.46 & 22.48 & 87.68 \\
\hline 10 & -10 & 0 & 0 & 59.93 & 89.23 & 91.90 & 4.40 & 4.34 & 4.14 & 47.65 & 93.45 & 94.60 & 14.43 & 78.79 & 70.97 \\
\hline 10 & 0 & -10 & 0 & 62.77 & 63.45 & 96.86 & 4.36 & 4.17 & 3.98 & 48.55 & 50.09 & 98.35 & 16.94 & 18.07 & 98.04 \\
\hline 10 & 0 & 0 & -10 & 57.71 & 76.98 & 88.46 & 4.10 & 4.01 & 3.87 & 47.91 & 87.72 & 93.18 & 19.45 & 86.66 & 89.64 \\
\hline 10 & 10 & -10 & -10 & 91.42 & 88.47 & 99.98 & 4.07 & 4.01 & 3.86 & 81.82 & 80.10 & 100.00 & 54.99 & 21.42 & 99.61 \\
\hline 10 & -10 & 10 & -10 & 72.28 & 99.69 & 98.63 & 4.07 & 4.01 & 3.86 & 59.58 & 99.88 & 95.88 & 21.82 & 99.45 & 69.38 \\
\hline 10 & -10 & -10 & 10 & 87.63 & 91.82 & 99.93 & 4.07 & 4.01 & 3.86 & 79.35 & 82.72 & 99.97 & 20.18 & 57.25 & 99.67 \\
\hline
\end{tabular}


Table 2. Percentage of times particular break dates are selected using the innovational outlier test with $\hat{T}_{B}=\operatorname{argmax} F_{\delta}$, when seasonal mean shifts occur under the null: $T=100$.

\begin{tabular}{|c|c|c|c|c|c|c|c|c|c|c|c|c|c|}
\hline$\kappa_{1}$ & $\kappa_{2}$ & $\kappa_{3}$ & $\kappa_{4}$ & $<T_{B}{ }^{\prime}-7$ & $T_{B}{ }^{\prime}-7$ & $T_{B}{ }^{\prime}-6$ & $T_{B}{ }^{\prime}-5$ & $T_{B}{ }^{\prime}-4$ & $T_{B}{ }^{\prime}-3$ & $T_{B}{ }^{\prime}-2$ & $T_{B}{ }^{\prime}-1$ & $T_{B}{ }^{\prime}$ & $>T_{B}$ \\
\hline 5 & 5 & 5 & 5 & 1.73 & 0.34 & 1.21 & 3.70 & 85.36 & 1.72 & 1.12 & 0.25 & 0.00 & 4.57 \\
\hline 5 & 0 & 0 & 0 & 15.49 & 15.29 & 10.85 & 14.45 & 24.97 & 0.18 & 0.28 & 0.30 & 0.68 & 17.51 \\
\hline 5 & 5 & 0 & 0 & 5.66 & 4.02 & 23.21 & 18.35 & 39.70 & 2.80 & 0.11 & 0.12 & 0.10 & 5.93 \\
\hline 5 & 0 & 5 & 0 & 5.38 & 3.21 & 2.16 & 31.15 & 47.73 & 1.64 & 2.42 & 0.02 & 0.08 & 6.21 \\
\hline 5 & 0 & 0 & 5 & 5.63 & 6.55 & 3.71 & 4.09 & 65.58 & 1.39 & 2.31 & 4.17 & 0.18 & 6.39 \\
\hline 5 & 5 & 5 & 0 & 2.49 & 1.51 & 5.61 & 28.55 & 54.56 & 3.10 & 0.67 & 0.01 & 0.05 & 3.45 \\
\hline 5 & 5 & 0 & 5 & 1.91 & 0.98 & 5.13 & 3.64 & 75.62 & 8.55 & 0.54 & 0.86 & 0.04 & 2.73 \\
\hline 5 & 0 & 5 & 5 & 1.78 & 1.15 & 0.72 & 8.31 & 75.99 & 2.40 & 6.15 & 0.52 & 0.01 & 2.97 \\
\hline 5 & -5 & 0 & 0 & 5.75 & 4.39 & 22.83 & 18.61 & 38.92 & 2.77 & 0.04 & 0.07 & 0.15 & 6.47 \\
\hline 5 & 0 & -5 & 0 & 6.93 & 5.02 & 2.32 & 40.45 & 31.74 & 1.70 & 3.40 & 0.17 & 0.35 & 7.92 \\
\hline 5 & 0 & 0 & -5 & 6.26 & 6.50 & 3.95 & 4.09 & 65.45 & 1.09 & 2.15 & 3.82 & 0.10 & 6.59 \\
\hline 5 & 5 & -5 & -5 & 1.24 & 0.74 & 1.50 & 11.80 & 78.73 & 1.36 & 2.67 & 0.25 & 0.05 & 1.66 \\
\hline 5 & -5 & 5 & -5 & 1.95 & 0.43 & 1.08 & 3.95 & 84.87 & 1.89 & 0.88 & 0.31 & 0.00 & 4.64 \\
\hline 5 & -5 & -5 & 5 & 1.36 & 0.93 & 1.50 & 11.44 & 78.68 & 1.53 & 2.32 & 0.30 & 0.09 & 1.85 \\
\hline 10 & 10 & 10 & 10 & 0.00 & 0.01 & 0.04 & 0.17 & 99.17 & 0.30 & 0.13 & 0.02 & 0.00 & 0.16 \\
\hline 10 & 0 & 0 & 0 & 0.40 & 20.59 & 13.19 & 23.75 & 41.62 & 0.01 & 0.02 & 0.00 & 0.03 & 0.39 \\
\hline 10 & 10 & 0 & 0 & 0.06 & 0.32 & 23.36 & 18.29 & 57.65 & 0.25 & 0.00 & 0.00 & 0.01 & 0.06 \\
\hline 10 & 0 & 10 & 0 & 0.08 & 0.08 & 0.09 & 34.51 & 64.74 & 0.26 & 0.13 & 0.00 & 0.00 & 0.11 \\
\hline 10 & 0 & 0 & 10 & 0.01 & 0.65 & 0.28 & 0.37 & 97.63 & 0.11 & 0.21 & 0.67 & 0.00 & 0.07 \\
\hline 10 & 10 & 10 & 0 & 0.00 & 0.03 & 1.16 & 28.20 & 69.97 & 0.60 & 0.03 & 0.00 & 0.00 & 0.01 \\
\hline 10 & 10 & 0 & 10 & 0.00 & 0.00 & 0.17 & 0.23 & 96.11 & 3.38 & 0.05 & 0.04 & 0.00 & 0.02 \\
\hline 10 & 0 & 10 & 10 & 0.00 & 0.00 & 0.00 & 1.86 & 94.09 & 0.50 & 3.53 & 0.00 & 0.00 & 0.02 \\
\hline 10 & -10 & 0 & 0 & 0.04 & 0.42 & 22.97 & 19.29 & 56.95 & 0.26 & 0.00 & 0.00 & 0.00 & 0.07 \\
\hline 10 & 0 & -10 & 0 & 0.11 & 0.28 & 0.13 & 56.88 & 41.62 & 0.24 & 0.60 & 0.00 & 0.01 & 0.13 \\
\hline 10 & 0 & 0 & -10 & 0.02 & 0.63 & 0.32 & 0.36 & 97.55 & 0.07 & 0.23 & 0.81 & 0.00 & 0.01 \\
\hline 10 & 10 & -10 & -10 & 0.00 & 0.00 & 0.00 & 1.60 & 97.94 & 0.09 & 0.36 & 0.01 & 0.00 & 0.00 \\
\hline 10 & -10 & 10 & -10 & 0.02 & 0.02 & 0.03 & 0.14 & 99.26 & 0.25 & 0.10 & 0.06 & 0.00 & 0.12 \\
\hline 10 & -10 & -10 & 10 & 0.01 & 0.00 & 0.00 & 1.58 & 98.03 & 0.12 & 0.25 & 0.00 & 0.00 & 0.01 \\
\hline
\end{tabular}


Table 3. Critical values of innovational outlier seasonal unit root tests with $\hat{T}_{B}=4+\operatorname{argmax} F_{\delta}$.

\begin{tabular}{|c|c|c|c|c|c|c|c|c|c|}
\hline & \multicolumn{3}{|c|}{$t_{1}$} & \multicolumn{3}{|c|}{$t_{2}$} & \multicolumn{3}{|c|}{$F_{34}$} \\
\hline & $10 \%$ & $5 \%$ & $1 \%$ & $10 \%$ & $5 \%$ & $1 \%$ & $10 \%$ & $5 \%$ & $1 \%$ \\
\hline$T=52$ & -3.01 & -3.35 & -3.94 & -3.02 & -3.34 & -3.99 & 8.08 & 9.50 & 12.77 \\
\hline$T=100$ & -3.24 & -3.54 & -4.15 & -3.21 & -3.52 & -4.12 & 8.87 & 10.11 & 12.90 \\
\hline$T=152$ & -3.30 & -3.61 & -4.17 & -3.26 & -3.55 & -4.17 & 9.18 & 10.52 & 13.49 \\
\hline$T=200$ & -3.36 & -3.66 & -4.24 & -3.35 & -3.66 & -4.19 & 9.44 & 10.84 & 13.48 \\
\hline$T=500$ & -3.52 & -3.80 & -4.35 & -3.51 & -3.82 & -4.37 & 9.99 & 11.40 & 14.34 \\
\hline
\end{tabular}

Table 4. Empirical sizes of nominal 5\%-level innovational outlier seasonal unit root tests with $\hat{T}_{B}=4+\operatorname{argmax} F_{\delta}$, allowing for seasonal mean shifts: $T=100$.

\begin{tabular}{rrrrccc}
\hline$\kappa_{1}$ & $\kappa_{2}$ & $\kappa_{3}$ & $\kappa_{4}$ & $t_{1}$ & $t_{2}$ & $F_{34}$ \\
\hline 5 & 5 & 5 & 5 & 2.68 & 4.43 & 6.16 \\
5 & 0 & 0 & 0 & 3.73 & 4.22 & 4.39 \\
5 & 5 & 0 & 0 & 2.84 & 4.43 & 4.17 \\
5 & 0 & 5 & 0 & 3.05 & 3.01 & 5.27 \\
5 & 0 & 0 & 5 & 3.35 & 4.87 & 5.17 \\
5 & 5 & 5 & 0 & 2.80 & 3.68 & 5.57 \\
5 & 5 & 0 & 5 & 2.83 & 3.52 & 4.55 \\
5 & 0 & 5 & 5 & 2.83 & 4.51 & 4.11 \\
5 & -5 & 0 & 0 & 4.80 & 2.94 & 4.18 \\
5 & 0 & -5 & 0 & 5.03 & 4.82 & 3.60 \\
5 & 0 & 0 & -5 & 4.89 & 3.38 & 5.27 \\
5 & 5 & -5 & -5 & 3.94 & 4.41 & 3.72 \\
5 & -5 & 5 & -5 & 4.16 & 2.78 & 6.19 \\
5 & -5 & -5 & 5 & 4.73 & 4.21 & 3.92 \\
10 & 10 & 10 & 10 & 2.59 & 2.86 & 3.19 \\
10 & 0 & 0 & 0 & 2.65 & 2.71 & 3.12 \\
10 & 10 & 0 & 0 & 2.72 & 2.99 & 3.23 \\
10 & 0 & 10 & 0 & 2.69 & 2.64 & 3.18 \\
10 & 0 & 0 & 10 & 2.70 & 3.08 & 3.24 \\
10 & 10 & 10 & 0 & 2.65 & 2.87 & 3.69 \\
10 & 10 & 0 & 10 & 2.65 & 2.55 & 3.11 \\
10 & 0 & 10 & 10 & 2.56 & 3.79 & 3.12 \\
10 & -10 & 0 & 0 & 2.80 & 2.58 & 3.13 \\
10 & 0 & -10 & 0 & 3.05 & 2.98 & 3.04 \\
10 & 0 & 0 & -10 & 3.00 & 2.74 & 3.29 \\
10 & 10 & -10 & -10 & 2.85 & 3.41 & 3.24 \\
10 & -10 & 10 & -10 & 2.82 & 2.67 & 3.17 \\
10 & -10 & -10 & 10 & 3.37 & 3.02 & 3.18 \\
\hline & & & & & &
\end{tabular}

